\title{
"MARÍA LUISA VILLALBA» Y LA TARDE
}

\author{
Juana González González \\ Universidad de La Laguna
}

\section{RESUMEN}

El presente trabajo trata de dar a conocer los inicios como periodista de María Rosa Alonso, concretamente su colaboración con el periódico La Tarde. Tenía veinte años cuando con el seudónimo de "María Luisa Villalba» se atreve a escribir artículos periodísticos. A comienzos del siglo xx estaba mal visto que una señorita escribiera en los periódicos, por eso para evitar «encontronazos», principalmente con su madre, decide ocultar su verdadera identidad. Después se pasa a situar a la joven escritora en el contexto histórico de las primeras décadas del siglo xx, se hace una comparación con María Joaquina de Viera y Clavijo, que en el siglo de la Ilustración también realizó labores no esperables en la época para la condición femenina y que comparte varias similitudes con la periodista. Se habla del periódico La Tarde, de su historia y de cómo la confianza que puso Víctor Zurita, director del diario vespertino, en la estudiosa joven fue decisiva para que se iniciara una fructífera relación profesional. Además, se hace una clasificación temática de los artículos, en la que se da un pequeño resumen con algunas valoraciones personales de todos y cada uno siguiendo el orden cronológico.

Palabras Clave: María Rosa Alonso, periodismo, La Tarde.

"MARÍA LUISA VILLALBA» AND LA TARDE

\section{Abstract}

The present work focuses on the first steps of María Rosa Alonso as journalist, specifically her collaboration with the newspaper $L a$ Tarde. At that time, she was only twenty years old and she dared to write articles under the pseudonym «María Luisa Villalba». At the beginning of the 20 th century it was frowned upon for a woman to write in the journals, and in order to avoid problems, principally with her mother, she decided to silence her true identity. Later this work deals with the young writer in the historical context of the first decades of the xxth century, with a comparison with María Joaquina de Viera y Clavijo, a woman who during the Enlightment also carried out works that, at the time, were unexpected for the feminine condition. Her life shares several similarities with the journalist. We focus on the newspaper La Tarde, its history and how the trust that Víctor Zurita, director of that evening journal, placed in the young scholar was decisive for the beginning of a fruitful professional relationship. We present a thematic classification of her articles, in which we include a brief abstract with some personal assessments, always following the chronological order.

Keywords: María Rosa Alonso, journalism, La Tarde. 


\section{INTRODUCCIÓN. EL CONTEXTO HISTÓRICO}

María Rosa Alonso (1909-2011) escribió bajo el seudónimo de «María Luisa Villalba», desde su primer artículo publicado en La Tarde el 29 de enero de 1930 hasta el 5 de febrero de 1933. Debido a las gestiones que realizó para poner en marcha el Instituto de Estudios Canarios, por el que tanto había luchado, su verdadera identidad quedó al descubierto. Para Eliseo Izquierdo la época en la que publica bajo este seudónimo constituye «un capítulo fundamental de su vida de escritora, acaso el más genuinamente periodístico, el de más combatividad y el de mayor carga política e ideológica, con el que se labró, celando siempre su identidad, un prestigio muy sólido, al que la Guerra Civil y la posguerra inmediata pusieron sordina» (VV.AA. 2010: 375).

Para entender mejor esta actitud de María Rosa Alonso, vamos a situarnos en el contexto histórico del tercer decenio del siglo xx en Canarias. Ya desde finales del siglo XIX, se venía respirando un aire de cambios en cuanto a la mujer dentro de la sociedad: la izquierda aceptó de una forma muy suave la necesidad del voto femenino, mientras que la derecha defendía un tipo de mujer sin capacidad de razonar por sí misma. La realidad era que la mujer necesitaba al marido para tomar cualquier tipo de decisión y, si era soltera, dependía del padre o de los hermanos.

Diputadas como, por ejemplo, Clara Campoamor lograron el voto para las mujeres, la Ley del divorcio llegó en 1932 y la Ley del aborto solo se llevó a cabo en Cataluña. La diputada Victoria Kent luchó por una mejora del nivel educativo, sobre todo en lo que concernía a la escolarización de las nińas; lo anterior trajo como consecuencia un aumento considerable del número de estas en las aulas. En Canarias, la llegada de la II República constituyó un gran avance en la cultura, la sociedad y la política, que convergieron en una reforma de la educación y en una modernización ideológica. Se empezó a luchar para aminorar las altas tasas de analfabetismo, el caciquismo político y las duras condiciones de vida de una población eminentemente rural (Alonso de la Vega 2019). Veamos lo que nos dice María Rosa Alonso sobre esta evolución:

Después comenzaron las mujeres a estudiar. Primero carreras estimadas por los caballeros «muy femeninas» como las de Farmacia o Filosofía y Letras; luego de una manera lenta, las mujeres se atrevieron con Derecho, Medicina (¡qué escándalo!); enfilaron todas o casi todas las fuentes del saber humano y las hay hasta fiscales: ¡el colmo! [...] De lo que se trata es de trabajar en lo más conveniente y, además de la suerte, juega un gran papel en su elección la inteligencia, preparación y laboriosidad del sujeto que trabaja. Nunca he sido "feminista» y mis lectores lo saben, desde que vengo escribiendo, pero sí me parece justo que, en códigos, trabajos, derechos y deberes seamos los humanos todos iguales, que todos seamos sujetos, pero no que unos (o que unas) sean objeto (el caso más ostensible es el de la prostitución) o «segundo sexo». Vamos a jugar sin trampas de que «la reina eres tú» y cositas así. De libertad no se habla. Libertad no tiene mucha, hoy día casi nadie. La libertad, en general, no se da. La libertad se gana (Alonso 2009: 203-209). 


\section{DOS PIONERAS}

Hasta la época en que empezó a escribir María Rosa Alonso muy pocas mujeres habían destacado en la sociedad isleña, quizás una de las primeras guarda algunas similitudes con nuestra periodista. Se trata de María Joaquina de Viera y Clavijo (1807-1819), hermana del ilustrado canario por antonomasia José de Viera y Clavijo (Fraga 1985-1987: 319-333). También en el quehacer político y literario de María Rosa Alonso fue muy importante la influencia de su hermano, Elfidio Alonso Rodríguez (Rodríguez Padrón: 2005).

Ambas escritoras fueron pioneras en actividades que no realizaban las mujeres en su época: María Rosa Alonso se dedicó al periodismo, que hasta el momento estaba consagrado al mundo de los hombres. María Joaquina (Galván González 1999: 123-128) escribía poesía y algo de prosa, está considerada como la primera mujer escritora dentro de la tradición literaria canaria. Las dos, al ser solteras, tuvieron que cuidar a sus padres hasta su fallecimiento; además, María Joaquina se dedicó a cuidar de sus dos hermanos sacerdotes, por lo que se trasladó a vivir a Las Palmas, ya que ellos ejercían allí su ministerio.

Ahora bien, mientras que la familia Viera gozaba de una buena posición social y económica, la familia de María Rosa Alonso era humilde: su madre ejercía de maestra en Guamasa, aunque eran naturales de Tacoronte. Cuando nuestra escritora tiene once años se trasladan a vivir a La Laguna, donde cursa su bachillerato en el Cabrera Pinto, hoy Instituto de Canarias:

En el verano de 1927 aprueba en la Facultad de Derecho de la Universidad de la Laguna las asignaturas del primer curso, que entonces era común con Filosofía y Letras, su intención es ir a estudiar la carrera de Filosofía y Letras a Madrid, pero no puede realizar entonces ese proyecto (Martinón 2007: 9).

Sus condiciones económicas le impidieron seguir con sus estudios universitarios, por lo que tiene que trabajar muy duro para conseguir su sueño de ir a estudiar a la capital del Estado. Precisamente esta es la época de su relación con La Tarde.

María Joaquina era natural del Puerto de la Cruz, pero para ella fue crucial la época que vivió en La Laguna, donde tuvo «contacto con los ambientes ilustrados, y va a ser en este momento cuando comience a aprender y a ejercitar sus inquietudes artísticas» (Perera Santana 2019: 1). Otra etapa muy importante fue la que compartió con su hermano en Gran Canaria, que es cuando cultivará en mayor medida la poesía. Unido a la actividad literaria, también realizaba retratos laicos de tipo escultórico en barro, actividad totalmente inédita en una mujer en el siglo XVIII: «sus obras de arte no llegaron al espacio comercial, pero le obligaron a tomar conciencia de los problemas artísticos, a pesar de que ella se consideraba "una mujer sin reglas de escultura” (Palacios Fernández 2021: 1).

La relación entre ambas escritoras, aquí meramente apuntada, debe ser objeto de un análisis más profundo y objetivo de un próximo trabajo. Ellas marcaron un antes y un después en sus respectivas dedicaciones, en ambas había una gran vocación por las letras, pero su trayectoria creativa fue muy diferente. Para 
María Joaquina, ni la escritura ni la escultura constituyeron su medio de vida; en cambio, para María Rosa Alonso el periodismo sí que fue una profesión, que compartió con la docencia.

\section{3. $L A T A R D E$}

Para hablar de María Rosa Alonso y su relación con el periodismo, concretamente con el diario vespertino $L a$ Tarde, tenemos que tener muy presente que eligió el género periodístico que mejor se adecuaba a sus intenciones: el artículo de opinión. Era una forma de expresar sus ideas políticas y cualquier manifestación de índole cultural, de ahí que ella hablaba de su labor comunicadora como "periodismo cultural». Pero también lo hizo consciente de que era una dedicación no apta para mujeres, puesto que hasta el momento las escritoras canarias se habían dedicado, sobre todo, a la poesía. El principal escollo a sortear era el propio ambiente familiar, que al fin y al cabo es el reflejo de la sociedad, por ello emplea un seudónimo para que su madre no supiera de su actividad «tan poco femenina».

El periódico La Tarde salió a la calle el 1 de octubre de 1927, momento crítico de la historia del Archipiélago, pues acababa de dividirse en dos la provincia única de Canarias, que tenía, hasta entonces, por capital a Santa Cruz de Tenerife. Fueron sus fundadores don Víctor Zurita Soler, don Matías Real González y don Francisco González Viera. El diario se caracterizará desde sus comienzos por una defensa de los ideales e intereses tinerfeños, según palabras del profesor de la Universidad de La Laguna Julio Antonio Yanes Mesa:

Indudablemente, el proyecto más atinado de los años 20 fue el diario vespertino de Santa Cruz La Tarde. Nacido en 1927 tras la división provincial bajo la dirección de Víctor Zurita, el nuevo diario tinerfeńo sintonizó tan acertadamente con su contexto, que a una línea editorial genuinamente informativa, y que servía a deshora de La Prensa, añadió el radical tinerfeñismo demandado en la Isla por el reciente "despojo», lo que, al unísono, lo catapultaron tras los pasos del diario de Leoncio Rodríguez. Con tales bases, en los años de la República era el segundo periódico de la Isla (Yanes Mesa 1998: 269-270).

También nos dice el doctor Yanes que la inmediata consolidación de La Tarde y su éxito empresarial se explicaron por el ingrediente tinerfeñista. Esta característica coyuntural supo dar a una línea editorial en la que, a su vez, primaba la información sobre el compromiso político. A lo largo de sus cincuenta y cinco años de existencia trató de mantener, siempre que le fue posible, el carácter de medio de información independiente. Fue un periódico pobre en recursos económicos, pero rico en iniciativas y en logros ciudadanos; tanto en la larga etapa en que fue dirigido por don Víctor Zurita como durante el tiempo en que lo dirigió Alfonso García-Ramos.

María Luisa Villalba fue, sin duda alguna, uno de los escasos ganchos con los que contó el periódico para ganarse la simpatía del público, dado que la joven bachiller, con su juventud, el hecho de ser mujer y las perspectivas rompedoras desde las 
que planteaba sus propuestas encarnó, en una sociedad tan agraria y tradicional como es la isleña, la voz de la Nueva España que, con tantas esperanzas, nacía bajo el ropaje republicano (VV.AA. 2010: 360-361).

No se olvide que la República trajo aires regionalistas hasta el entonces tinerfeñismo, defendido por la división provincial decretada en 1927. El profesor Yanes destaca cómo en las islas fue María Rosa Alonso la primera pluma femenina que apareció con regularidad en la tribuna periodística. Ella abordaba temas políticos y culturales que, hasta el momento, habían sido considerados patrimonio de los varones.

\section{LOS ARTÍCULOS EN LA TARDE}

En este apartado analizaremos los treinta y un artículos que se publicaron en La Tarde desde el 29 de enero de 1930 al 11 de julio de 1931. El análisis lo haremos siguiendo la temática que se trata en ellos.

\subsection{Periodismo cultural}

Así llamaba María Rosa Alonso a su forma de hacer periodismo; ella era consciente del bajo nivel cultural que había en Canarias y quería aportar sus conocimientos académicos e ideas. Su empeńo era que, sobre todo, la juventud adquiriera conciencia del trabajo a realizar, para que las islas fueran adquiriendo el lugar que merecían dentro del Estado español.

En su primer artículo, «En torno a los libros de la guerra» (29 de enero de 1930), empieza hablando de una novela fantástica, La catástrofe, de Nicolás Tassín. Dice que es muy fácil hacer una clasificación de las edades de la historia, ya desde este primer artículo demuestra su interés por los estudios históricos. Hace hincapié en la juventud que participa en el diario El Sol, y en su afán por buscar la verdad; pone como ejemplo los libros de la guerra, es decir, los que la juventud encuentra sinceros. Para demostrar lo anterior, habla de un ensayo, Los que teníamos doce años, de Ernesto Glaeser, que la ha conmovido fuertemente. En dicha obra se destaca la valentía de la juventud frente a la indignación de la masa burguesa. Acaba el artículo con una especie de himno, con el que anima a la juventud a enfrentarse a los que quieren la guerra, defendiéndose con las armas de la sinceridad.

"Las bibliotecas populares» (18 de octubre de 1930) nos cuenta como hay una biblioteca en Gijón, la Circulante, en la que destaca su catálogo con las correspondientes secciones. No puede evitar la pena de compararla con Tenerife, no solo en cuanto a las bibliotecas, sino a los demás estudios de «humanidades». Nombra a algunos investigadores, por ejemplo, a Rodríguez Moure, cita sus palabras en el prólogo al libro de Viana, donde critica el caciquismo y el espíritu mercantilista del pueblo isleño, pues los libros de asientos eran los únicos que les interesaban. Ella hace un llamamiento al milagro para que haya más preocupación por la cultura y los libros; pero duda mucho de que existan gentes preocupadas por esto. 
En «Juliano y el presente» (5 de noviembre de 1930) dice que estamos en un momento de transición y compara la civilización antigua con la actual. Nombra a Juliano el Apóstata, que buscaba el escepticismo (según Unamuno) y que en el siglo IV fue, como Oscar Wilde en el XIX, «un griego a desatiempo». El Apóstata añoraba lo viejo porque lo acercaba a Grecia, adoraba más el atardecer que el mediodía esplendoroso, más el otońo que la primavera. Lo que a la joven periodista le queda claro es que una época no vuelve porque lo quiera un hombre, aunque este sea el emperador. Y toda esta historia de Juliano viene a cuento porque en ese momento de transición se intenta inyectar sueros vitales a regímenes de gobierno por galenos decrépitos. Ella cree que todo esto no es sino porque los Julianos piden angustiados el «milagro».

«Para En Marcha» (27 de marzo de 1931) nos da a conocer el periódico obrero que se hace en Santa Cruz, que se publica quincenalmente. A ella se lo pasa un trabajador y compara sus manos con las del joven, porque, como bien había dicho Azorín, ambas manos son las de «hacedor de obra». En Marcha tiene nombre bélico, de tropa; los obreros, a la vez que luchan, también beben vino y a ella le parece que demasiado. Reprocha a la prensa isleńa que no nombre para nada este periódico de los obreros federados, afirma que este adjetivo suena muy mal a «los contratistas, autoridades, caciques, señoras gruesas, etc.». Continúa animando a los trabajadores de En Marcha. Hace una advertencia, parecida a la que hizo Ortega en Segovia, cuando dijo que no le dieran las gracias porque «nunca pido nada al que mucho estima, aun cuando mucho dar pueda».

En «De nuestro presente y porvenir» (16 de junio de 1931) comienza hablando de Ortega y Gasset y de su diálogo con el diario El Sol, a raíz de los conceptos orteguianos que aparecían en Misión en la Universidad. Esto da lugar a que María Rosa Alonso critique un periodismo poco pulcro, que se deja llevar por la «irritación biológica» y por otros defectos. Más adelante habla de Tenerife y de $L a$ Tarde, en el que ella ha pretendido crear una opinión contrastándola con otros sectores de prensa. Hace una encendida defensa de este periódico vespertino, recordando temas como la universidad o el regionalismo; con respecto a este último nombra a la revista Cartones y a García Cabrera. Y termina el artículo con una exhortación a los políticos, para que despierten y se dediquen a luchar por la región.

\subsection{La JUVENTUd}

Cuando escribió su primer artículo nuestra autora tenía veinte años, por lo que conocía muy bien las inquietudes propias de la edad. Ella se siente capacitada para dar consejos de cómo debe actuar la juventud ante la política, ya pudimos comprobarlo en su primer artículo, al hablar de los libros de la guerra.

En su segundo artículo, «Mirando al siglo XIX» (6 de febrero de 1930), dice que la juventud busca paz y serenidad, este deseo queda reflejado en el afán de dejar los nacionalismos y buscar el internacionalismo. Ella sigue defendiendo la paz frente a los desastres de la guerra, sobre todo los de las guerras civiles; pone como ejemplo a Unamuno con su lucha por defender sus ideales. Vuelve a hablar de la juventud 
que se expresa en El Sol y termina el artículo haciendo un llamamiento a la comprensión, al trabajo y a la serenidad.

Las mismas ideas vuelven a aparecer en el artículo "Del problema del español: gobernantes y gobernados» (13 de abril de 1930), quinto del bloque, donde incluso vuelve a hablar de Unamuno como un intelectual que protestó por la dictadura de Primo de Rivera.

En «La juventud y la agricultura, I» (11 de agosto de 1930) nombra a los jóvenes del 27 que se dedicaron al terreno literario y artístico; mientras que España era llevada a la ruina, ellos se refugiaban en su religión gongorina. La juventud es por naturaleza vanguardista y toda vanguardia es batalladora. En el momento en que nuestra autora escribe el artículo, ella cree que la juventud debe intervenir en la política. Destaca la necesidad de que se trate todo lo que tiene que ver con la agricultura, puesto que esta solo es conocida por el campesino. Hay que crear la escuela rural de capacitación agraria, la juventud debe ir «al campo como anteriormente fue al arte y la literatura y como hoy intenta ir a la política». Jóvenes que teniendo sus propias tierras, en vez de estudiar para abogados, deberían estudiar para ser buenos agrónomos.

En «Don Antonio Lugo y Massieu, II» (12 de agosto de 1930) habla de este señor que dirige el periódico gratuito El campo desde hace quince años. También cita a don Amado Zurita, que pidió para don Antonio un premio, pero nadie le hizo caso. Tampoco atendieron a don Antonio G. Beltrán cuando escribió sobre campos agrícolas. Y en un alarde de ironía, habla de la cruz otorgada a un secretario de Estado por haber publicado el embarazo de la reina; por eso no le haría ninguna gracia que el nombre de don Antonio Lugo estuviera al lado del dicho secretario. Finalmente, se queja de que la gran cruz que tiene que llevar D. Antonio sea la de «la incomprensión isleña, donde todo se condecora con la indiferencia y el olvido».

En «Las dos oraciones» (18 de octubre de 1930), el título del artículo hace alusión a dos tipos de oraciones: por un lado, la de un seglar que canta a la libertad, don Niceto Alcalá Zamora; y la de un eclesiástico, que desde el púlpito alaba las excelencias de la Roma del papa. Habla de Ortega y de su idea de que España renacerá de las provincias o no renacerá. Dice que una vez pasados los días, aquellas voces también quedaron en el olvido; tal y como dijo Machado, «cae una monotonía de lluvia en los cristales». En Tenerife solo se puede confiar en la juventud, la que grita. Aunque también hay algunos sectores dignos con «deseos de civilidad, de regionalismo, de mirar al campo y dar la tierra a los que la surcan y la aman, de romper las ligaduras y las mordazas que anidan ya en muchos corazones».

\subsection{CRÍticA LITERARIA}

Como buena estudiante y lectora que era, la crítica literaria aparece desde su primer artículo, ahí habla de los libros de la guerra con la finalidad de convencer a la juventud de que rechace los conflictos bélicos.

En su tercer artículo, «Mirando al siglo XIX, II» (10 de febrero de 1930), relaciona crítica e historia al hablar de la Revolución francesa y del liberalismo, al que 
define como un valor puro y positivo del siglo xix. En este contexto aparece la gran obra Hernani, que representa el decaimiento de la aristocracia de reyes absolutos. De la misma manera, acaba el auge de la tragedia apareciendo el triunfo de la plebe, de las masas, reflejado en el cambio de metro y rima de la poesía. Del siglo xix destaca como positivos dos valores: el amor y el liberalismo puro.

En «Un libro de Gutiérrez Albelo» (23 de junio de 1930), llama la atención el subtítulo (Escrito para La Tarde), creemos que porque, hasta el momento, no había escrito ningún artículo dedicado en su totalidad a la crítica literaria. La escritora comienza hablando de la aparición de dos publicaciones: la revista Cartones y el libro Campanario de la primavera, de Gutiérrez Albelo. De la revista dice que no la ha podido conseguir, ya que es privilegio de una aristocracia, de una selecta minoría. Entre este grupo se encuentra el mejor poeta marino de Tenerife, el único que ha interpretado un sentido regionalista del mar: Pedro García Cabrera. Ella tampoco pertenece al círculo de amigos de Gutiérrez Albelo, pero ha leído su libro y le parece íntimo, donde el sentimiento desconcierta, en parte. Su autor, afirma nuestra crítica literaria, «... no es poeta canario, es poeta de Canarias, del interior, de lo íntimo, pero no del aislamiento autóctono, sino de lo interior e íntimo de cualquiera geografía». La relación entre Gutiérrez Albelo y María Rosa Alonso fue muy interesante ${ }^{1}$, no en vano al año siguiente él le dedicó la poesía «La savia obscura» a María Luisa Villalba, que incluyó en su libro Romanticismo y cuenta nueva (1933: 217-218).

El siguiente artículo en publicar en La Tarde, el 30 de junio de 1930, también fue de crítica literaria: «En torno a la revista Cartones», a la que había nombrado en su anterior artículo. Al hablar de que el arte y la literatura no son recinto cerrado, nos cita una frase aparecida en un semanario político: «Todo hombre por humilde que sea tiene derecho a ser jefe del Estado». Dicha frase representa, para nuestra autora, la característica fundamental de la cultura: que toda persona puede llegar a ella; por eso aplaude la aparición de la revista Cartones. Nos habla de cómo en el siglo pasado en la escuela Normal de maestros, Luis de Zulueta se quejaba de que la juventud leía poco. María Rosa Alonso no está de acuerdo con esa afirmación y pone como ejemplo la aparición de esta revista. Hace un amplio comentario de los que participan en la publicación, pero destaca por encima de los demás autores a Pedro García Cabrera y a Carmen Jiménez.

«Motivos de un centenario», 12 de septiembre de 1930: la autora utiliza en este artículo un lenguaje muy rebuscado para referirse a Hernani, que representó el rompimiento con el pasado y supuso el nacimiento del Romanticismo; para Victor Hugo simbolizaba el «liberalismo» en la literatura. Habla ampliamente del movimiento romántico en Francia y en Espańa, que trajo consigo la Constitución de 1812 y sucesivas. En el artículo aparecen citados textualmente diálogos de Hernani. Hace

1 Para entender mejor la relación entre estos dos escritores, es muy interesante el artículo de Rafael Fernández Hernández «María Rosa Alonso, vista por Emeterio Gutiérrez Albelo y Domingo Pérez Minik», en VV.AA. (2010): 213-230. 
referencia al centenario 1830-1930, homenajea el nacimiento de un movimiento literario-histórico, que nada mas nacía ya empezaba a morir. Hace una exaltación al triunfo social que nos queda de esa época, el triunfo del pueblo, termina con una frase muy poética: «Hacia un lado del horizonte, está inclinado el vértice rojo de nuestro corazón».

«Un libro de Valbuena Prat», 15 de junio de 1931: pide disculpas por haberse dedicado a las líneas políticas y no atender a este libro. Su autor fue catedrático de la Universidad de La Laguna, la que le debe mucho; en el momento de la publicación a comentar, el profesor está en la Universidad de Barcelona. La obra se titula Literatura dramática española, y la comentarista deja bien claro que Valbuena fue el animador de un grupo «que aireó nuestro infestado campo con esencias distintas y por entonces actuales». Dio a conocer la poesía canaria, sus trabajos fueron un punto de partida para sus seguidores. También hace alusión a un libro de Valbuena sobre la nueva poesía, que no ha llegado a Canarias, ella cree que, si dicho libro se hubiese publicado, habría tenido éxito de venta. A lo largo del artículo hace un resumen del contenido de la obra, alaba la cuidadosa edición y las ilustraciones hábilmente seleccionadas, que han constituido un éxito tanto para la editorial como para Valbuena Prat.

\subsection{La POLÍ́TICA}

La política ocupó un lugar muy importante en la juventud de María Rosa Alonso. Empieza a escribir un año antes de la llegada de la II República, en sus artículos vemos reflejada la intensidad con la que vivió los vaivenes de la política del momento.

En primer lugar, tenemos su cuarto artículo, que ya desde el título nos deja evidencia del tema que va a tratar, "Interrogantes acerca de la política», publicado el 13 de febrero de 1930. Sigue con el tema de la juventud y la política, esta vez haciendo alusión a La Gaceta Literaria. Esta revista hizo una especie de encuesta entre la juventud, para saber su concepto de "política», pero los jóvenes no dieron respuestas claras. La periodista llega a la conclusión de que a la gente sí le interesa la política y hablar de ella; por ejemplo, Francisco Ayala siente la política como espectáculo y sobre todo como actuación, mientras que otros diferencian el hombre del artista. Sigue planteando muchas preguntas acerca de la política con sus inevitables elecciones, presentándose situaciones tan curiosas como cuando les preguntan a los agricultores por quién van a votar, y ellos dicen que por el amo; o cuando a los maestros se les dice que tienen que votar por el diputado que apoya el cacique. Y termina con una referencia poética: «¿Volverán... las oscuras golondrinas?...».

También tenemos un bloque de siete artículos con el título «Del problema español: gobernantes y gobernados», publicados entre marzo y abril de 1930. Todos tienen como eje central la política, pero en cada uno de ellos hay detalles muy interesantes.

En el primero, publicado el 24 de marzo, destacamos la referencia a artículos de Ortega y Gasset escritos en el 27, dedicados a la Constitución. Decía que, 
según algunos, era mala porque se abusaba de ella, pero él creía que lo que pasaba es que se abusaba de ella porque era mala.

En el siguiente artículo, publicado el 27 de marzo, María Rosa Alonso sigue hablando de Ortega y de sus "clases abstractas» formadas por burócratas, intelectuales y financieros, que forman una minoría frente a la mayoría formada por el campesinado. Ella dice que en Espańa no se supo hacer uso del sufragio universal, porque lo que sucedió es que cada elector vendió su voto al cacique de turno. En esto se resume el liberalismo español.

En el artículo del día 31 de marzo, sigue con Ortega. Hace referencia a las palabras del filósofo sobre el no cumplimiento de la Constitución de 1876, por lo que en España no ha habido Parlamento. La articulista dice que siempre se habla del pueblo, pero no se cuenta para nada con él; el pueblo, para tener derechos, tiene que contar con los deberes. En el último párrafo resume muy bien sus ideas: «iQué voluntad dichosa! Si la voluntad nacional no ha imperado es porque el pueblo no ha tenido ninguna».

En «Explotadores y explotados» (3 de octubre de 1930), la escritora cuenta la dura realidad de los obreros que hacen la carretera de El Tanque a Erjos; en contraposición, habla del señorito que pasea en su coche comprado con el dinero de "papá», que es el que explota a los trabajadores. Habla de la historia, teniendo en cuenta las teorías marxistas. Insiste, en contra de algunos teóricos, en que el pueblo no "pasa» del Gobierno. Al pueblo sí le importa la forma de gobierno porque si no, no habría socialistas, ni comunistas, ni anarquistas. Aunque al final es el dinero lo que importa, los que quedan son explotadores y explotados. Continúa haciendo alusión a una frase de cualquier encargado hacia los reclamos del trabajador: «Al que no le interesa que se marche». La anterior frase es similar a la de María Antonieta, cuando se le hablaba del pueblo hambriento de pan: «Si no tienen pan, que coman tortas!». Mas lo cierto fue que las "tortas" las tuvo que comer ella». Nótese la ironía de la periodista.

En «Ayer, hoy y el cacique» (20 de diciembre de 1930) comienza describiendo una habitación en la que hay muchos libros. A continuación, hay un diálogo entre un viejo, que tiene un gato, y un mozo; se trata de un cacique y un obrero en un día de huelga, el joven dice que los piquetes no le dejaron ir a trabajar. El viejo le reprocha el lenguaje que el carretero -tal es su profesión- emplea, al cacique le parece que el obrero sabe demasiado de sindicalismo y le censura que lea la prensa obrera. El trabajador se enfrenta al jefe, diciéndole que no va a trabajar ese día; el cacique, al no poder maltratar físicamente al joven porque este se fue a toda prisa, mata al gato con el bastón. El último párrafo es muy poético: «Mientras allá por la venta del Frasco, unos cohetes son luminosa tiza con la que unos agrietados dedos escriben "Liberación" en la negra y lejana pizarra de los cielos".

En «Ha terminado el siglo XIX» (22 de abril de 1931) inicia su artículo de una forma muy lírica haciendo referencia a Antonio Machado, a su deseo de que el alba quisiera entrar por el fondo de los sueños de los hombres del 98. Para ella, el sueño se ha cumplido y es la República, que está representada en prestigiosos intelectuales: Francisco de los Ríos, Albornoz, Largo Caballero..., es decir, el trabajo y la inteligencia, la decencia nacional organizada. Hace un repaso por los desastres 
del xix y los primeros treinta ańos del xx, un balance nefasto. Pero todo esto ha acabado, España entra a formar parte de la mejor categoría de las naciones europeas. Ella no pide la venganza, sino la serenidad y la justicia.

En «Un alto en la marcha y jadelante!» (25 de mayo de 1931) la periodista emplea un tono pesimista, al hablar de otros artículos cargados de ilusión sobre la República: «Pero los tinglados de la vieja farsa se construyen de nuevo»; dice que la España de 1931 hace una revolución de tipo viejo régimen europeo. Y se hace preguntas como: «¿Es esta la evolución que España -la "España vital” que José Ortega y Gasset ansiaba?». Al mes de la llegada de la República, ve como los gobernantes siguen comportándose como siempre, por lo que cree que el Gobierno no ha escuchado la voz del pueblo, cuando este ha irrumpido ansioso y fervoroso a pedir el cambio. Aunque nuestra autora mantiene la esperanza de que al gritar «iViva la Libertad!» se consiga esta y de que «el solar se fabrique con nuevos obreros y, sobre todo, con nuevos cimientos».

En «Socialistas en La Laguna» (11 de julio de 1931), a pesar de declararse en deuda con los socialistas laguneros, ella no quiere identificarse con ningún partido. Pero lo que sí le preocupa es que los obreros no se unan para reivindicar sus derechos y que, además, haya muchos que estén al lado de partidos que no los representen, cosa que le parece muy nefasta. Dice que en La Laguna se ha organizado el partido socialista, le parece que esta corriente, junto con la sindicalista y a la comunista, tienden al mismo fin: al mejoramiento de la clase obrera. Habla de que ningún partido burgués «llámese republicanos radicales, sociales, derechas, etc.», puede representar a los trabajadores. Estos, si son laguneros deben estar unidos a sus compañeros socialistas, ya sean de La Laguna, de Santa Cruz..., porque para ella más hermano es un obrero santacrucero que un burgués lagunero.

\subsection{INSULARISMO/REGIONALISMO/CENTRALISMO}

A pesar de que es un tema político, hemos preferido ponerlo en otro apartado, puesto que nuestra autora le dedicó bastante espacio a la preocupación que sentía por la división entre las islas.

En el primer artículo del bloque «Del problema español: gobernantes y gobernados", del 24 de marzo, habla del centralismo; en concreto, dice que solo los de Madrid están bien enterados de las cosas que pasan en el Parlamento. Por eso allí es donde únicamente se hacen elecciones «normales y auténticas».

El tercer artículo del bloque, del 31 de marzo: dice que hay que organizar al pueblo en torno a la gran comarca, no al municipio ni a la provincia. Según su teoría, se trata de unir nueve o diez grandes comarcas, es decir, a la región. Esta era la idea de Ortega y Gasset, que no llegó a terminar de darle forma. En conclusión, María Rosa Alonso se declara defensora del regionalismo, que ella ve así: «¡Cuán distinta sentimos Vasconia de Andalucía, Galicia de Cataluña, Canarias del resto de las regiones; nuestros problemas, indiosincracia, arte y aun cantos populares...!».

En el cuarto artículo del bloque, del 7 de abril, opina directamente de "autonomía regional»; cuando se refiere a "falsas elecciones» dice que el pueblo está 
manipulado. No se puede pretender que un «rural» de Canarias elija a un diputado, para que en Madrid discuta acerca de temas de Derecho político o de una Ley de Instrucción pública. Ella dice que no quiere militar en afirmaciones gratuitas, pero que mientras que no se emprenda una gran reforma con miras a una autonomía regional, España no tendrá nunca un verdadero Parlamento.

En el correspondiente al 13 de abril habla de Santa Cruz y lo compara con Madrid. Por ejemplo, un vecino de Buenavista o Guía no elegiría para la capital con tanto conocimiento a un alcalde de Santa Cruz como lo haría un santacrucero. Cuanto más cerca un asunto, más claro se ve. Dicho ejemplo le sirve para reivindicar sus ideales de autonomía regional.

En el artículo del 14 de abril, sexto del bloque «Del problema del español: gobernantes y gobernados", trata el tema de las «minorías» y de que estas tienen el deber de transformar. Para lograr esas transformaciones están las escuelas, volviendo a reivindicar la autonomía regional, ya que las escuelas pueden sacar a las provincias de su "ruralismo». Pero primero hay que hacer una premisa-axioma con una autonomía regional, hay que borrar las líneas provinciales y encerrarlas en el marco de la región.

En el séptimo y último artículo del bloque, del 17 de abril, hace un llamamiento para que Canarias no se dedique a «esperar». Pide que se abandone esa pretendida "abulia», que es solo un cómodo mito. No se debe usar ese acostumbrado "Aquí no se puede hacer nada", porque hay que intentarlo con amor, fe y constancia. Insta a la Asociación de Estudiantes a seguir con sus cursos de conferencias, aunque ellos mismos deberían intervenir más a menudo. Habla de la posibilidad de hacer una revista, elogia al Círculo de Bellas Artes por su gran sentido cultural, y ella se considera romántica, ya que espera y cree en una España nueva.

En el artículo publicado el 8 de mayo con el título de «Otro voto que se pierde», presenta la dicotomía centralismo/provincianismo. Afirma que Madrid no tiene cultura propia, que cuando se viene de allí, no se aplica aquí lo aprendido; puesto que se recuerda con nostalgia lo vivido allá y se mira lo de aquí con indiferencia y desdén. La nueva orientación debe ir por sendas culturales, es aquí donde aparece el nombre propio al que está dedicado el artículo, don Salvador Quintero. Este proponía un centro de estudios tinerfeños -el germen del Instituto de Estudios Canarios-, pensando en el comercio de la isla, sin tener en cuenta ni la ideología ni la edad. María Rosa Alonso deposita su voto en la misma urna que el Sr. Quintero, aunque se pierdan en un recipiente donde los "culturales deseos provinciales" le han abierto el fondo.

«Autonomía» (9 de marzo de 1931) habla de la tradición religiosa de don Santiago, un magnífico predicador de Valle Guerra, este sacerdote, que escribe en Gente Nueva, es «un hombre al día». En su sermón habla de la península (Madrid, Cádiz), alude a damas de alcurnia, una que representa a la reina. El sacerdote hace un repaso a los desastres coloniales, ruega que respeten nuestra historia y que no nos manden aves de rapiña a destrozarnos: «que nos traten como hermanos y no como parias». La articulista termina con una reflexión sobre la autonomía, recordando las palabras de don Nicolás Estévanez: «autonomía aislamiento celular dentro del organismo de la Nación». Dice que hasta ella ha llegado una pregunta formulada 
en esos días: «¿Cómo se estructuraría Canarias, autonómicamente, dentro de un estado federal?».

\subsection{La EdUCACIÓN}

En el artículo «Del problema del español: gobernantes y gobernados» (14 de abril), sexto del bloque, María Rosa Alonso nos dice que para que un elector vaya a votar debería haber pasado antes por la escuela primaria. La solución sería el carácter gratuito y obligatorio de estos centros educativos. Aunque desde los catorce, que acaba la primaria, hasta los veinticinco, en que se puede votar, el elector se puede olvidar de lo aprendido. Pero si hay una buena escuela de adultos nocturna, conferencias..., lo anterior se puede salvar. Habla del lema adoptado en Rusia sobre la escuela: «Hay que ir al alma del niño». Hacen falta muchos maestros, muchas escuelas; también escuelas normales para preparar maestros. Critica algunos aspectos de la enseñanza de Magisterio: dura cuatro años, echa en falta la Filosofía, más prácticas escolares, la Didáctica...; no se está al día en los modernos procedimientos y orientaciones pedagógicas. Por último, critica el que la escuela normal sea una sucursal de congregaciones religiosas exclusivamente.

En el séptimo y último artículo del bloque sigue con el tema: reclama más sueldo para los maestros. Habla de su situación en Canarias, sobre todo de la económica, que el Estado se niega a mejorar porque, según los políticos, son muchos maestros.

«De la reforma del Bachillerato» (24 de julio de 1930) empieza diciendo que la Constitución del 76 ha sufrido un nuevo zarpazo. El artículo $3 .^{\circ}$ : «Al Estado corresponde expedir títulos profesionales», ahora el Estado delega la función en el catedrático, que en un examen escrito al final del sexto año, valorará sí el alumno merece el título de bachiller. Esto lo ve nuestra autora como una mordaza, ya que no se tienen en cuenta los claustros: el informe que estos hacían para aprobar a los futuros bachilleres. Los claustros habían surgido el año anterior "como mensajeros de la libertad». María Rosa Alonso cree que con esta nueva reforma se fortalece el capitalismo y otros determinados sectores sociales. Además de separar a los jóvenes, "cuyo único pecado es no tener padres suficientemente ricos», es una separación que también se quiere imponer a los institutos femeninos: «Separar a los que mañana por ley de la vida marcharán juntos. Fomentar hipocresías, crear barreras...».

\subsection{LA MUJER}

En el artículo escrito el 30 de junio de 1930 sobre la revista Cartones, cuando se refiere a la poetisa Carmen Jiménez, lo hace llamándola poeta: «aunque sea nombre de mujer yo digo de ella como Azorín de Rosalía de Castro: el poeta». No deja de ser curiosa esta apreciación, teniendo en cuenta que precisamente ella, por su condición femenina, tiene que firmar con un seudónimo, al estar realizando una labor periodística hasta el momento desempeñada solo por varones. 
En su artículo sobre el periódico obrero En Marcha del 27 de marzo de 1931, dedica un párrafo a la mujer. Comienza diciendo que siempre ha querido eludir el hablar de mujeres en sus artículos, porque al hablar de ellas, habla o escribe sobre sí misma. Esta vez hace una salvedad, porque en un ejemplar de En Marcha le han llamado la atención unas líneas contundentes, escritas por una obrera, Peregrina Armas. Esta invita de manera clara a las mujeres a que se afilien a los sindicatos, pues cree que es una imperiosa necesidad. La obrera termina con una frase de Marx: «La manifestación del obrero debe ser obra del mismo». María Rosa Alonso emplea unas palabras dignas de una mujer escritora y comprometida con sus ideas políticas y sindicales: "Todas mis simpatías para esta obrera que lee a Marx o que sabe solamente de Marx esta frase. Ella le basta para no olvidar y saber que se salvará sola o no se salvará».

El 22 de abril de 1931, en su artículo "Ha terminado el siglo XIX», da una visión muy positiva del momento político y cultural que está viviendo España, con la llegada de la II República. Pero el último párrafo demuestra claramente la discriminación que esta ella viviendo por ser mujer:

Queremos erigir un nuevo Estado. Mi lugar es el de una muchacha que no puede salir de casa sin licencia de su padre, y que en el caso peregrino de tener caudal para adquirir un palacio no lo podrá comprar tampoco, sin la licencia de su padre.

\subsection{EL AMOR}

Dedica a este tema su quinto artículo, «De la decadencia del Amor», publicado el 24 de febrero de 1930: la autora se hace muchas preguntas sobre qué es el amor para los jóvenes actuales. Hace un repaso por la poesía del xvini y «El canto a Teresa» (xIx) de Espronceda. Continúa describiendo las diferencias en cuanto al amor en la literatura de los dos siglos; por ejemplo, Manón Lescaut/Margarita Gautier, estableciendo las diferencias eróticas entre las dos heroínas. En el siglo XIX, con el movimiento romántico, se hablaba siempre del amor: al pueblo, al arte..., hablar de un músico era hablar de sus amores; no había pudor, se hablaba de las intimidades de todo el mundo. Ahora bien, al llegar al siglo xx hay cambios: la vida íntima de un hombre actual es distinta a su vida artística. La consideración del amor como intimidad es, para María Rosa Alonso, uno de los mejores aciertos del siglo xx.

\subsection{El ARTE}

En su primer artículo, «En torno a los libros de la guerra», defiende la visión del arte como creación frente a la destrucción de la guerra.

En el tercero, "Mirando al siglo XIX, II», al hablar del Romanticismo, dice que en dicho siglo se abusó de la igualdad en el arte, confundiendo igualdad y libertad. El Romanticismo lo que hizo fue intentar reparar la humillación que la masa había sufrido en el siglo XviII, para ello se humanizó el arte. 
En el artículo «Del problema del español: gobernantes y gobernados» (14 de abril), sexto del bloque, comienza hablando del arte y su relación con las dictaduras, ambos son considerados impopulares. El arte pretende ser de minorías, negando la realidad a la masa -aquí como sinónimo de pueblo-, el pueblo no es como pensaron los del XIX, sino como pensaron las «minorías».

También nos encontramos una referencia al arte y la literatura, en el artículo del 30 de junio, que habla de la revista Cartones: nos dice que la pureza del arte está en la minoría, pero el sino de la masa es alcanzarle, educarse, trabajar, anhelar y, sobre todo, molestarse. Unas líneas más adelante, vuelve a decir que «Ricos y pobres» en arte es la adaptación de la tradicional máxima burguesa, conservadora: la gran propiedad (el dueño) y el trabajador (el esclavo). En fin, vemos como ella emplea un lenguaje muy preciso, cargado de referencias políticas, ya que estaba viviendo una época muy combativa.

\subsection{El ÚlTimo arTículo}

«Socialistas en La Laguna», del 11 de julio de 1931, fue el último artículo que María Rosa Alonso publicó en el periódico La Tarde bajo el seudónimo de «María Luisa Villalba». Su siguiente artículo en el diario vespertino sería el 14 de junio de 1946, ya firmado con su verdadero nombre. Los motivos por los que dejó de publicar en el periódico tinerfeño creemos que están relacionados con la aparición de Proa, un nuevo periódico de izquierdas:

... tras las elecciones de abril de 1931, nació Proa, obra de Elfidio Alonso, Ernesto Pestana Nóbrega y Antonio Guillermo Cruz en el seno de la Juventud Republicana, adoptando un inequívoco posicionamiento de izquierda que, en materia regional, le llevó a propugnar un consenso, lo que le valió fuertes censuras del periódico tinerfeñista por antonomasia de entonces La Tarde... (Yanes Mesa 1996: 45).

No en vano, nos encontramos con un artículo de María Rosa Alonso en el nuevo periódico que nos aporta información sobre el tema:

"El problema canario», también publicado el mismo día, que apareció por última vez con el seudónimo de "María Luisa Villalba» en La Tarde, es decir, 11 de julio de 1931. Ella cree que la juventud debe opinar ante un asunto tan trascendental para las islas -el año anterior había escrito sobre el regionalismo en un periódico gomero, donde trataba la polémica que hubo entre La Tarde de Santa Cruz de Tenerife y un periódico de Las Palmas-, defendía que el regionalismo no existía ya, sino una rivalidad, que desde la época de Cairasco de Figueroa y de Antonio de Viana estaba presente. «No se puede discutir lo que no se ama», con esta frase explica su posición ante un tema del que parecen huir algunos pero que para ella es muy importante, pues forma parte de nuestra realidad regional. Continúa diciendo que ha sido convocada una asamblea para tratar de la elaboración de un Estatuto canario: Canarias es una región con dos cabezas, pero le falta cabeza para serlo. A ella le preocupa el despertar de las islas menores, pues parece que solo las capitalinas tienen derecho a discutir. Habla del historiador don Dacio Darias Padrón, de Pedro García Cabrera y 
de La Prensa, que están de acuerdo en sacar adelante el proyecto, frente al periódico La Tarde, que lo tacha de "mediocre y ridículamente materialista, lleno de pasión, desprovisto de serenidad...». Termina diciendo que no es solo su persona la que se inclina por una solución «izquierdista, ausente de 'petit' nacionalismos hitlerianos conocedora de las realidades. De unos modestos pero firmes destinos».

En un listado de sus artículos, que nos facilitó la misma María Rosa Alonso, aparece uno que creemos que sería muy esclarecedor para saber más sobre ella y el periódico vespertino. Se trata de "La Tarde y yo", Proa, Santa Cruz de Tenerife, 25 de julio de 1931. Pero tras muchas indagaciones, no hemos podido localizar el citado periódico, que creemos que hubiera sido un buen epílogo para este trabajo. Pero seguiré buscándolo...

\section{CONCLUSIÓN}

La principal dificultad para clasificar por temas los artículos de «María Luisa Villalba» ha sido que en un mismo artículo se pueden encontrar varios. Ya dijimos al comienzo de este trabajo que ella lo que se propuso fue hacer lo que llamaba "periodismo cultural». Teniendo en cuenta que la cultura está constituida por una gran variedad de temas, abarcados por la actividad humana, no nos puede extrañar que nuestra autora escribiera de todo lo que creía conveniente, para comunicar sus ideas en cada uno de sus textos.

Es muy importante, también, observar cómo una joven de veinte años en una provincia tan alejada de la capital del Estado, que es donde ella ansiaba estar estudiando, se enfrenta con múltiples problemas, destacando el económico y su condición femenina. Pero está dispuesta a luchar para conseguir realizar sus sueños: busca recursos, como, por ejemplo, escribir con un seudónimo, para salir adelante y convertirse en la primera mujer periodista de Canarias. El periódico vespertino La Tarde le da la gran oportunidad de poder expresarse por escrito, publicando sus ideas políticas, literarias, etc. La joven estudiante pretendía, con su labor periodística, poder influir en la juventud en particular y en el público en general. Era una época de cambios ilusionantes para los estudiantes, los trabajadores y la gente de izquierda, que se encontraban en los prolegómenos de la II República.

Sus artículos son ejemplo de una escritura precisa, impecable y ferviente, tanto en el orden estilístico como en el ideológico. Con un lenguaje sencillo, pero a la vez tan bien expresado, nos lleva al conocimiento de su ideología política, de su inquietud por la historia, por la música, la pintura... También expresa sus ansias de cambio en una Espańa que va a iniciar un nuevo rumbo político. Tiene fe en una juventud de la que forma parte, pues es la edad propicia para luchar por una sociedad mejor, más culta dentro de una región, tan diferente del resto del Estado español.

Con esta pequeña muestra de los comienzos como periodista y mujer luchadora de la joven María Rosa Alonso, hemos pretendido poner nuestro granito de arena para el conocimiento de esta gran figura de las letras canarias. 


\section{BIBLIOGRAFÍA}

Alonso, María Rosa (2009²): La ciudad y sus habitantes, Sociedad Estatal de Conmemoraciones Culturales y el Gobierno de Canarias: 202-205.

Alonso de Vega, Inés (2019): «Feminismo canario en el siglo xX», en https://inesalonsodevega. com/2019/02/05/feminismo-canario/ (consultado el 12/02/2021).

Fraga González, Carmen (1985-1987): «María Viera y Clavijo en el ambiente artístico de los ilustrados en Canarias", El Museo Canario, XLVIII: 319-333.

Galván González, Victoria (1999): «El motivo de la cruz en la poesía de María de Viera y Clavijo», Anuario del Instituto de Estudios Canarios, XLIII: 123-138.

Gutiérrez Albelo, Emeterio (1933): Romanticismo y cuenta nueva, Santa Cruz de Tenerife: Ed. Gaceta de Arte.

Martinón, Miguel (2007): «María Rosa Alonso en su biblioteca», Imagen de María Rosa Alonso. Exposición bibliográfica y documental Día del libro 2007, Universidad de La Laguna.

Palacios Fernández, Emilio: http://dbe.rah.es/biografias/68812/maria-joaquina-viera-y-clavijo (consultado el 22/05/2021)

Perera Santana, José Miguel (2019): https://www3.gobiernodecanarias.org/medusa/ecoescuela/ escritorascanarias/?p $=332$ (consultado el 24/05/2021)

Rodríguez Padrón, Jorge (2005): «Homenaje a Elfidio Alonso Rodríguez en el centenario de su nacimiento. 1905-2001», https://www.bienmesabe.org/noticia/2005/Octubre/homenajea-elfidio-alonso-rodriguez-en-el-centenario-de-su-nacimiento (consultado 15/02/2021)

VV.AA. (2010): Entre las dos orillas: Maria Rosa Alonso y los Estudios Canarios, La Laguna: Instituto de Estudios Canarios.

Yanes Mesa, Julio Antonio (1996): «El periodismo republicano en Tenerife (1868-1936): alborada, plenitud y ocaso de una prensa política», Tebeto. Anuario del Archivo Histórico Insular de Fuerteventura IX: 25-50.

Yanes Mesa, Julio Antonio (1998): «Del proselitismo ideológico a la información y la interpretación de la noticia: panorama retrospectivo, a medio y corto plazo, del periodismo contemporáneo en Tenerife, 1898-1991", Boletín Millares Carlo, n. ${ }^{\circ}$ 16, 269-70.

\section{Artículos De «María Luisa Villalba» en LA TARDE}

«En torno a los libros de la guerra», 29 de enero de 1930.

«Mirando al siglo XIX, II», 10 de febrero de 1930.

«Interrogantes acerca de la política», 13 de febrero de 1930.

«De la decadencia del Amor», 24 de febrero de 1930.

«Del problema español: gobernantes y gobernados, I», 24 de marzo de 1930.

II: 27 de marzo. III: 31 de marzo de 1930. IV: 7 de abril. v: 11 de abril.

vi: 14 de abril. vir: 17 de abril de 1930 .

«Otro voto que se pierde», 8 de mayo de 1930.

«Un libro de Gutiérrez Albelo», 23 de junio de 1930.

«En torno a la revista Cartones», 30 de junio de 1930. 
«De la reforma del Bachillerato», 24 de julio de 1930.

«La juventud y la agricultura, I», 11 de agosto de 1930.

«Don Antonio Lugo y Massieu, II», 12 de agosto de 1930.

«Motivos de un centenario», 12 de septiembre de 1930.

«Explotadores y explotados», 3 de octubre de 1930.

«Las bibliotecas populares», 18 de octubre de 1930.

«Las dos oraciones», 31 de octubre de 1930.

"Juliano y el presente», 5 de noviembre de 1930.

«Ayer, hoy y el cacique», 20 de diciembre de 1930.

"Autonomía», 9 de marzo de 1931.

«Para En Marcha», 27 de marzo de 1931.

«Ha terminado el siglo xIX», 22 de abril de 1931.

«Un alto en la marcha y jadelante!», 25 de mayo de 1931.

«Un libro de Valbuena Prat», 5 de junio de 1931.

«De nuestro presente y porvenir», 24 de junio de 1931.

«Socialistas en La Laguna», 11 de julio de 1931.

\section{Artí́culos en otros Periódicos}

«El problema canario», Proa, Santa Cruz de Tenerife, 11 de julio de 1931.

«El Instituto de Estudios Canarios, está en marcha», Hoy, Santa Cruz de Tenerife, 5 de febrero de 1933. 